\title{
Pengaruh Pitch Shift Up dan Pitch Shift Down Terhadap Tingkat Kemiripan Rekaman Suara
}

\author{
Ahmad Subki ${ }^{1}$, Erfan Wahyudi ${ }^{2}$, Achmad Syauqi ${ }^{3}$ \\ STMIK Mataram ${ }^{1,2}$ \\ Universitas Islam Indonesia ${ }^{3}$ \\ ahmad.subki1992@gmail.com
}

\begin{abstract}
Abstrak
Abstak - Rekaman suara merupakan alat bukti yang dapat digunakan untuk mengungkapkan suatu tindak pidana, akan tetapi dengan perkembangan teknologi terdapat banyak macam fitur terbaru dari aplikasi perekam suara itu sendiri. Salah satunya adalah dengan aplikasi voice changer yang dapat merubah pitch pada rekaman suara. Penelitian ini dilakukan untuk mengetahui tingkat pengaruh dari perubahan nilai pitch pada rekaman suara. Dari hasil penelitian ini diperoleh bahwa rekaman suara yang telah dirubah nilai pitchnya menggunakan aplikasi voice changer masih memiliki tingkat identik yang cukup tinggi. Akan tetapi untuk analisis pitch pada rekaman suara tidak satupun yang memiliki keidentikan, sehingga untuk kasus rekaman suara yang telah dirubah nilai pitchnya analisis pitch pada rekaman suara tidak dapat digunakan. Sedangkan untuk analisis formant dan spectogram masih dapat digunakan untuk menentukan keidentikan rekaman suara.
\end{abstract}

Kata kunci: rekaman suara,, pitch shift up, pitch shift down, formant, specgtogram

\section{Latar Belakang}

Maraknya kejahatan yag melibatkan barang bukti rekaman suara belakangan ini semakin sering terjadi. Hal ini dikarenakan perkembagan teknologi yang semakin cepat. Salah satunya adalah teknologi perekam suara. Rekaman suara dapat digunakan sebagai barang bukti elektronik untuk mengungkap suatu tindak pidana. Sebagaimana yang disebutkan dalam UUD ITE tahun 2016 Pasal 1 bahwa "Informasi Elektronik adalah satu atau sekumpulan data elektronik, termasuk tetapi tidak terbatas pada tulisan, suara, gambar, peta, rancangan, foto, electronic data interchange (EDI), surat elektronik (electronic mail), telegram, teleks, telecopy atau sejenisnya, huruf, tanda, angka, kode akses, simbol, atau perforasi yang telah diolah yang memiliki arti atau dapat dipahami oleh orang yang mampu memahaminya". Rekaman suara merupakan metadata yang digunakan untuk mendapatkan petunjuk, mulai dari identitas individu, lokasi kejadian, waktu dan sebagainya (Huizen, Ketut, Ari, \& Hostiadi, 2016).

Teknologi rekaman suara saat ini telah berkembang dengan berbagai macam fitur, salah satu fitur yang banyak ditemukan pada play store android yaitu aplikasi perubah suara (voice changer). Seiring dengan perkembangan teknologi multimedia dikenal sebuah teknik pitch shifting yang digunakan untuk mengubah suara manusia di bagian timbre dan pitch. Input suara manusia diolah dan dikomputasi dengan metode pitch shifting yaitu dengan melakukan perubahan input suara manusia (frekuensi suara) dengan memanfaatkan pergeseran pitch suara, sehingga output yang dihasilkan adalah suara manusia (frekuensi suara) yang berbeda tanpa mengubah kata yang diucapkan (Anandha, 2014). Selain itu (Anandha, 2014) menyebutkan bahwa Ada beberapa teknik pitch shifting yang biasa dilakukan yaitu meninggikan pitch (pitch shift up) dan merendahkan pitch (pitch shift down). Pitch shift up bertujuan untuk meningkatkan nilai frekuensi. Hasil dari pitch shift up akan membuat jarak antar pitch semakin rapat dengan kata lain semakin tinggi frekuensi. Pitch shift down bertujuan untuk menurunkan nilai frekuensi. Hasil dari Pitch shift down akan membuat jarak antar pitch semakin lebar dengan kata lain semakin rendah frekuensi. 


\section{Kajian Pustaka}

Beberapa penelitian sebelumnya yang dijadikan acuan yaitu (Subki, Sugiantoro, \& Prayudi, 2018) pada paper yang berjudul "Analisis Rekaman Suara Voice Changer dan Rekaman Suara Asli Menggunakan Metode Audio Forensik", pada paper ini menghasilkan kesimpulan bahwa rekaman suara pada kasus perubah suara voice changer dengan rekaman suara asli hanya bisa di analisis dengan pendekatan formant, graphical distribution dan spectogram. Sedangkan untuk analisis pitch tidak dapat digunakan.

(Wicaksono \& Prayudi, 2013), telah melakukan penelitian dengan membuat sebuah skema kasus sederhana, selanjutnya melalui skema kasus tersebut dilakukan sejumlah tahapan forensika untuk membuktikan kesamaan sumber suara pada barang bukti dengan rekaman suara sampling. Teknik yang digunakan adalah melalui pendekatan konsep pitch, analisis statistik Formant dan Bandwidth, graphical distribution dan spectrogram. Terdapat tiga tools utama yang digunakan dalam penelitian ini yaitu DC Live Forensics 7.5. untuk proses audio enhancement, Praat untuk pencarian informasi pada audio dan Gnumeric untuk menghitung nilai formant pada setiap kata yang diucapkan. Dengan menggunakan standar kecocokan 20 kata yang diacu oleh FBI maka hasil analisis menunjukkan bahwa barang bukti digital audio memiliki kesamaan dengan sampling audio yang direkam.

(Aligarh, Hidayanto, Si, 2016) melakukan pemeriksaan forensika audio untuk voice recognition dengan metode komparasi, yaitu membandingkan suara barang bukti (unknown samples) dengan suara yang direkam sebagai pembanding (known samples). Teori voice recognition tersebut menganalisis statistik pitch, formant, bandwith dan spectogram. Jika hasil voice recognition menunjukkan bahwa suara percakapan yang ada di dalam barang bukti sama identik dengan suara pelaku, maka dapat disimpulkan bahwa suara percakapan yang ada di dalam rekaman barang bukti adalah suara milik pelaku sehingga alat rekam suara tersebut dapat digunakan sebagai bukti yang kuat di pengadilan. Hasil yang didapatkan dari uji fornsik terhadap barang bukti suara, dengan menggunakan nilai pitch, formant, dan spectrogram, ternyata pelaku yang dimaksud memiliki ciri-ciri berjenis berjenis kelamin laki-laki dengan usia diatas 50 tahun.

\section{Metodologi Penelitian}

Berikut ini merupakan metode penelitian yang digunakan:



Figure 1. Metodologi Penelitian

Adapun penejelasan dari metode tersebut adalah sebagai berikut:

\section{a. Rekaman Suara}

Pada penelitian ini dimulai dengan merekam suara menggunakan smartphone asus. Terdapat hanya satu suara yang direkam dengan mengucapkan sebanyak 21 kata. Operasi sistem smartphone pada saat rekaman suara ini dilakukan yaitu menggunakan android versi 5.0.

b. Rekaman suara yang telah dirubah dan Rekaman Suara Asli

Pada tahapan ini, aplikasi perubah suara digunakan aplikasi sebagai berikut :

a. Voice changer A: Best voice changer version 1.3.80 dari MeiHillMan

b. Voice changer B: Voice changer versi 1.1.4 dari 9xgeneration

c. Voice changer C: Voice changer version 1.0.73 dari AndroidRock

\section{c. Proses Enhancement}

Proses enhancement pada rekaman suara perlu dilakukan untuk meningkatkan kualitas dari rekaman suara itu sendiri, namun menurut (Wicaksono \& Prayudi, 2013) menggunakan enhancement tetap akan berpengaruh terhadap hasil analisis pitch.

\section{d. Mengekstrak Rekaman Suara}

Proses ekstrak rekaman suara ini bertujuan untuk memecah rekaman suara yang utuh, menjadi perkata. Hal ini bertujuan untuk 
mendapatkan nilai pitch setiap kata yang diucapkan, sehingga dapat memudahkan dalam proses analisis.

\section{e. Analisis}

Untuk analisis rekaman suara yang digunakan pada penelitian ini yaitu:

1) Analisis Statistic Pitch Menurut (AlAzhar Nuh, 2011) Analisis pitch dilakukan dengan cara melihat kalkulasi terhadap perbedaan nilai pitch dari masing-masing rekaman suara voice changer dan rekaman suara asli. Karakter pitch dari masing-masing suara dibandingkan pada nila pitch minimum, nilai pitch maksimum dan nilai pitch mean (rata-rata) yang didapatkan menggunakan aplikasi Praat. Dari perbedaan nilai statistik pitch inilah yang nantinya dapat membantu menilai tingkat kemiripan dari rekaman suara.

\section{2) Analisis Formant dan Bandwith}

Terdapat dua tahapan pada proses analisis ini yaitu:

- Analisis statistik anova

Pada analisisi ini paling tidak dibutuhkan 3 formant yang akan dibandingkan yaitu formant 1 , formant 2 dan formant 3 . Menurut (AlAzhar Nuh, 2011) hasil IDENTIK pada rekaman suara didapatkan apabila formant 1, formant 2 dan formant 3 menunjukkan nilai Accepted. Hasil ini didapatkan melalui perbandingan perbandingan ratio $\mathrm{F}$ dan $\mathrm{F}$ critical, dan nilai probability $P$ (P-Value). Apabila nilai Ratio $F>F$ Critical dan $P$ Value > 0.5 maka hasil yang diperoleh adalah Accepted.

- Analisis statistik likelihood ratio

Analisis likelihood ratio bertujuan untuk memperkuat hasil dari analisis Anova pada tahap sebelumnya. (Subki et al., 2018) mengemukakan bahwa Analisis likelihood ratio digunakan untuk memperkuat hasil analisis Anova yang didapat sebelumnya dengan memberikan statement hipotesis mendukung penuntutan/perlawanan, karena anlisis likelihood ratio ini dapat menjelaskan seberapa levelanalisis yang mendukung hipotesis penuntutan maupun hipotesis perlawanan.

Adapun formula menurut (Al-Azhar Nuh, 2011) untuk analisis likelihood ratio ini dijabarkan sebagai berikut:

$$
L R=\frac{p(E \mid H p)}{p(E \mid H d)}
$$

\section{Sumber: Paper Audio Forensic: Theory and Analysis}

Dimana :

- LR merupakan likelihood ratio

- $p(E \mid H p)$ adalah hipotesis tuntutan (prosecution), yaitu known dan unknown samples berasal dari orang yang sama.

- $p(E \mid H d)$ adalah hipotesis perlawanan (defense), yaitu known dan unknown samples berasal dari orang yang berbeda.

Jika $\mathrm{LR}>1$, maka hal ini akan mendukung $p(E$ | $H p)$, sebaliknya jika LR $<1$, maka $p(E \mid H d)$ yang didukung. Untuk itu, haruslah nilai $p(E \mid$ $\mathrm{Hp}$ ) > 0.5 untuk menyimpulkan bahwa suara yang telah dirubah dengan voice changer dan suara asli memiliki kemiripan (identik) (Subki et al., 2018).

Untuk menguatkan statement, maka analisis likelihood ratio ini didukung oleh statement verbal menurut (Rose, 2002) sebagai berikut:

Tabel 1. Verbal Statement Pendukung Hipoteseis tuntutan

\begin{tabular}{|c|c|c|}
\hline LR & Verbal Statement & Keterangan \\
\hline$>10.000$ & $\begin{array}{l}\text { Very strong evidence } \\
\text { to support }\end{array}$ & \multirow{5}{*}{$\begin{array}{c}\text { Mendukung } \\
\text { hipotesis } \\
\text { tuntutan } \\
p(\mathrm{E} \mid \mathrm{H} p)\end{array}$} \\
\hline $\begin{array}{l}1.000- \\
10.000\end{array}$ & $\begin{array}{l}\text { Strong evidence to } \\
\text { support }\end{array}$ & \\
\hline $\begin{array}{l}100- \\
1.000\end{array}$ & $\begin{array}{l}\text { Moderately strong } \\
\text { evidence to support }\end{array}$ & \\
\hline $10-100$ & $\begin{array}{l}\text { Moderate evidence to } \\
\text { support }\end{array}$ & \\
\hline $1-10$ & $\begin{array}{l}\text { Limited evidence to } \\
\text { support }\end{array}$ & \\
\hline
\end{tabular}

Sumber: Forensic Speaker Identification

(Rose, 2002)

Dari tabel 1 di atas dapat kita lihat bahwa semakin besar nilai LR nya maka semakin kuat pula hiptosis tuntutannya.

Tabel 2. Verbal Statement Pendukung Hipoteseis Perlawanan 


\begin{tabular}{|c|c|c|}
\hline LR & Verbal Statement & Keterangan \\
\hline $1-0.1$ & $\begin{array}{l}\text { Limited evidence } \\
\text { against }\end{array}$ & \multirow{5}{*}{$\begin{array}{l}\text { Mendukung } \\
\text { hipotesis } \\
\text { perlwanan } \\
\text { p }(\mathbf{E} \mid \mathrm{Hd})\end{array}$} \\
\hline $0.1-0.01$ & $\begin{array}{l}\text { Moderate evidence } \\
\text { against }\end{array}$ & \\
\hline $\begin{array}{l}0.01 \\
0.001\end{array}$ & $\begin{array}{l}\text { Moderately strong } \\
\text { evidence against }\end{array}$ & \\
\hline $\begin{array}{l}0.001- \\
0.0001\end{array}$ & $\begin{array}{l}\text { Strong evidence } \\
\text { against }\end{array}$ & \\
\hline$<0.0001$ & $\begin{array}{l}\text { Very strong evidence } \\
\text { against }\end{array}$ & \\
\hline
\end{tabular}

Sumber: Forensic Speaker Identification (Rose, 2002)

Dari tabel 2 di atas dapat kita lihat bahwa semakin kecil nilai LR nya maka semakin kuat pula hiptosis perlawanannya.

\section{3) Analisis Graphical Distribution}

Pada tahapan ini dilakukan dengan tujuan untuk menggambarkan tingkat penyeberan setiap formant yang telah didapatkan pada tahapan sebelumnya, biasanya digambarkan dengan suatu perbandingan antara formant 1 vs formant 2 dan formant 2 vs formant 3 (AlAzhar Nuh, 2011).

\section{4). Analisis Spectogram}

Pada analisis spectogram berguna untuk melihat pola khas yang ada pada setiap formant rekaman suara. Menurut (Al-Azhar Nuh, 2011) apabila pada pengucapan suku kata tertentu dari suara yang telah dirubah dengan voice changer dan suara asli tidak menunjukkan suatu perbedaan yang signifikan maka dapat disimpulkan bahwa pengucapan kata-kata tersebut memiliki kesamaan spectrogram.

\section{Implementasi Sistem dan Hasil}

Rekaman suara yang digunakan pada penelitian ini mengacu kepada standar dari Federal Bureau of Investigation (FBI) yang disusun oleh (Koenig, 1986) yaitu bahwa rekaman suara yang layak untuk dilakukan analisis audio forensik adalah sebanyak 20 kata. Pada penelitian ini rekaman suara yang dianalisis sebanyak 21 kata "Bapak silahkan transfer saja dulu uangnya sebesar 20 juta nanti setelah itu barangnya yang dipesan akan dikirimkan tiga hari kemudian". Dari penelitian tersebut didapatkanlah hasil yaitu sebagai berikut:
Tabel 3. Hasil voice recognition pada rekaman suara menggunakan voice changer $A$ (Pitch Shift Up)

\begin{tabular}{|l|l|l|l|}
\hline Analisis & \multicolumn{1}{l}{$\begin{array}{l}\text { Jumlah } \\
\text { kata }\end{array}$} & \multicolumn{1}{l|}{ Identik } & $\begin{array}{l}\text { Tidak } \\
\text { Identik }\end{array}$ \\
\hline $\begin{array}{l}\text { Analisis } \\
\text { Pitch }\end{array}$ & 21 & 0 & 21 \\
\hline $\begin{array}{l}\text { Analisis } \\
\text { Formant }\end{array}$ & 21 & 19 & 2 \\
\hline $\begin{array}{l}\text { Analisis } \\
\text { Spectogra } \\
\text { m }\end{array}$ & 21 & 17 & 4 \\
\hline
\end{tabular}

Tabel 4. Hasil voice recognition pada rekaman suara menggunakan voice changer $A$ (Pitch Shift Down)

\begin{tabular}{|c|c|c|c|}
\hline Analisis & $\begin{array}{l}\text { Jumlah } \\
\text { kata }\end{array}$ & Identik & $\begin{array}{l}\text { Tidak } \\
\text { Identik }\end{array}$ \\
\hline $\begin{array}{l}\text { Analisis } \\
\text { Pitch }\end{array}$ & 21 & 0 & 21 \\
\hline $\begin{array}{l}\text { Analisis } \\
\text { Formant }\end{array}$ & 21 & 21 & 0 \\
\hline $\begin{array}{l}\text { Analisis } \\
\text { Spectogra } \\
\text { m }\end{array}$ & 21 & 21 & 0 \\
\hline
\end{tabular}

Tabel 5. Hasil voice recognition pada rekaman suara menggunakan voice changer $B$ (Pitch Shift Up)

\begin{tabular}{|l|l|l|l|}
\hline Analisis & \multicolumn{1}{l}{$\begin{array}{l}\text { Jumlah } \\
\text { kata }\end{array}$} & \multicolumn{1}{|l|}{ Identik } & $\begin{array}{l}\text { Tidak } \\
\text { Identik }\end{array}$ \\
\hline $\begin{array}{l}\text { Analisis } \\
\text { Pitch }\end{array}$ & 21 & 0 & 21 \\
\hline $\begin{array}{l}\text { Analisis } \\
\text { Formant }\end{array}$ & 21 & 19 & 2 \\
\hline $\begin{array}{l}\text { Analisis } \\
\text { Spectogra } \\
\text { m }\end{array}$ & 21 & 15 & 6 \\
\hline
\end{tabular}

Tabel 6. Hasil voice recognition pada rekaman suara menggunakan voice changer $B$ (Pitch Shift Down)

\begin{tabular}{|c|c|c|c|}
\hline Analisis & $\begin{array}{l}\text { Jumlah } \\
\text { kata }\end{array}$ & Identik & $\begin{array}{l}\text { Tidak } \\
\text { Identik }\end{array}$ \\
\hline $\begin{array}{l}\text { Analisis } \\
\text { Pitch }\end{array}$ & 21 & 0 & 21 \\
\hline $\begin{array}{l}\text { Analisis } \\
\text { Formant }\end{array}$ & 21 & 18 & 3 \\
\hline $\begin{array}{l}\text { Analisis } \\
\text { Spectogra } \\
\mathrm{m}\end{array}$ & 21 & 17 & 4 \\
\hline
\end{tabular}


Tabel 7. Hasil voice recognition pada rekaman suara menggunakan voice changer $C$ (Pitch Shift Up)

\begin{tabular}{|c|c|c|c|}
\hline Analisis & $\begin{array}{l}\text { Jumlah } \\
\text { kata }\end{array}$ & Identik & $\begin{array}{l}\text { Tidak } \\
\text { Identik }\end{array}$ \\
\hline $\begin{array}{l}\text { Analisis } \\
\text { Pitch }\end{array}$ & 21 & 0 & 21 \\
\hline $\begin{array}{l}\text { Analisis } \\
\text { Formant }\end{array}$ & 21 & 21 & 0 \\
\hline $\begin{array}{l}\text { Analisis } \\
\text { Spectogra } \\
\text { m }\end{array}$ & 21 & 14 & 7 \\
\hline
\end{tabular}

Tabel 8. Hasil voice recognition pada rekaman suara menggunakan voice changer $B$ (Pitch Shift Down)

\begin{tabular}{|l|l|l|l|}
\hline Analisis & $\begin{array}{l}\text { Jumlah } \\
\text { kata }\end{array}$ & Identik & $\begin{array}{l}\text { Tidak } \\
\text { Identik }\end{array}$ \\
\hline $\begin{array}{l}\text { Analisis } \\
\text { Pitch }\end{array}$ & 21 & 0 & 21 \\
\hline $\begin{array}{l}\text { Analisis } \\
\text { Formant }\end{array}$ & 21 & 21 & 0 \\
\hline $\begin{array}{l}\text { Analisis } \\
\text { Spectogra } \\
\text { m }\end{array}$ & 21 & 19 & 2 \\
\hline
\end{tabular}

Dari tabel di atas, dapat dilihat bahwa rekaman suara yang paling tinggi tingkat identiknya dalah rekaman suara voice changer A dengan metode Pitch Shifting Down. Sedangkan rekaman suara voice changer B memiliki tingkat identik yang paling rendah dibandingkan dengan yang lain. Sebagaimana dapat dilihat pada figure 2 .

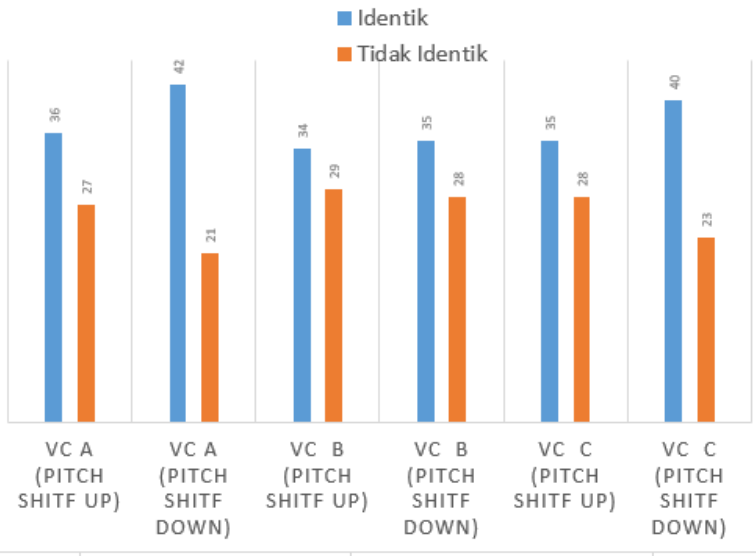

Figure 2 Perbandingan Tingkat Kemiripan Rekaman Suara
Perbedaan tingkat identik rekaman suara ini dikarenakan adanya perubahan nilai pitch pada masing-masing rekaman suara. Rekaman suara dapat dipengaruhi oleh faktor alpha $(\alpha)$ dan beta $(\beta)$, yang merupakan parameter time streching (alpha) dan pitch shifting (beta) (Hernawan, Tritoasmoro, \& Wijayanto, 2012).

\section{Pentutup}

Berdasarkan hasil penelitian di atas, dapat disimpulkan bahwa perubahan nilai Pitch pada rekaman suara dapat mempengaruhi keidentikan daripada rekaman suara tersebut. Bahkan dari hasil penelitian, setalah rekaman suara dirubah pitchnya baik menggunakan teknik (pitch shift up dan pitch shift down) tidak ada satupun suara yang memiliki keidentikan. Sehingga untuk analisis audio forensik hanya dapat digunakan 2 analisis yaitu analisis formant dan analisis spectogram, sedangkan untuk analisis pitch tidak dapat digunakan.

\section{Pustaka}

\section{UU ITE Tahun 2016}

Al-Azhar Nuh, M. (2011). AUDIO FORENSIC: Theory and Analysis, 1-38.

Aligarh, A., Hidayanto, C., Si, S., \& Kom, M. (2016). Implementasi Metode Forensik dengan Menggunakan Pitch , Formant , dan Spectrogram untuk Analisis Kemiripan Suara Melalui Perekam Suara Telepon Genggam Pada Lingkungan yang Bervariasi, 5(2).

Anandha, A. (2014). Transformasi Pitch Suara Manusia Menggunakan Metode PSOLA, 2(2), 129-151.

Hernawan, M. N. F., Tritoasmoro, I. I., \& Wijayanto, I. (2012). IMPLEMENTASI DAN ANALISIS KONVERSI SUARA MENGGUNAKAN ALGORITMA PITCH SHIFTING DENGAN TIME DOMAIN PITCH SYNCHRONOUS OVERLAP ADD ( TDPSOLA ).

Huizen, R. R., Ketut, N., Ari, D., \& Hostiadi, D. P. (2016). Model Acquisisi Rekaman Suara Pebanding Di Audio Forensik, 6-7.

Koenig, B. E. (1986). Spectrographic voice identification: a forensic survey. The Journal of the Acoustical Society of America, 79(6), 2088-2090.

https://doi.org/10.1121/1.393170

Rose, P. (2002). Forensic Speaker Identification. 
SciencesNew York (Vol. 20025246). https://doi.org/10.1201/9780203166369

Subki, A., Sugiantoro, B., \& Prayudi, Y. (2018). Analisis Rekaman Suara Voice Changer dan Rekaman Suara Asli Menggunakan Metode Audio Forensik. Indonesian Journal on Networking and Security (IJNS), 7(1). Retrieved from http://ijns.org/journal/index.php/ijns/article/vie $w / 39 / 38$

Wicaksono, G., \& Prayudi, Y. (2013). Teknik Forensika Audio Untuk Analisa Suara Pada Barang Bukti Digital. Semnas Unjani. 